\title{
काms
}

\section{Analysis of phylogeny, distribution, and pathogenicity of Botryosphaeriaceae species associated with gummosis of Anacardium in Brazil, with a new species of Lasiodiplodia}

\author{
Mariote S. B. NETTO ${ }^{a}$, Waléria G. LIMA ${ }^{a}$, Kamila C. CORREIA ${ }^{b}$, \\ Christiana F. B. DA SILVA ${ }^{c}$, Michael THON ${ }^{d}$, Ricardo B. MARTINS ${ }^{e}$, \\ Robert N. G. MILLER ${ }^{f}$, Sami J. MICHEREFF ${ }^{a}$, Marcos P. S. CÂMARA ${ }^{a, *}$ \\ ${ }^{a}$ Departamento de Agronomia, Universidade Federal Rural de Pernambuco, 52171-900 Recife, Pernambuco, Brazil \\ ${ }^{\mathrm{b}}$ Centro de Ciências Agrárias e da Biodiversidade, Universidade Federal do Cariri, 63133-610 Crato, Ceará, Brazil \\ 'Embrapa Agroindústria Tropical, 60511-110 Fortaleza, Ceará, Brazil \\ ${ }^{\mathrm{d}}$ Centro Hispano Luso de Investigaciones Agrarias (CIALE), Universidad de Salamanca, 37185 Villamayor, Spain \\ ${ }^{\text {e}}$ Campus Arapiraca, Universidade Federal de Alagoas, 57309-005 Arapiraca, Alagoas, Brazil

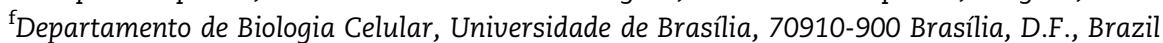

\section{A R T I C L E I N F O}

Article history:

Received 26 February 2016

Received in revised form

28 June 2016

Accepted 8 July 2016

Available online 21 July 2016

Corresponding Editor:

Geoffrey Gadd

\section{Keywords:}

Aggressiveness

Cashew

EF1- $\alpha$

ITS

Tropical fruit

\begin{abstract}
A B S T R A C T
Netto, M. S. B., Lima, W. G., Correia, K. C., da Silva, C. F. B., Thon, M., Martins, R. B., Miller, R. N. G., Michereff, S. J., and Câmara, M. P. S. 2016. Analysis of phylogeny, distribution, and pathogenicity of Botryosphaeriaceae species associated with gummosis of Anacardium in Brazil, with a new species of Lasiodiplodia. We identified Botryosphaeriaceae species associated with gummosis on Anacardium in Brazil. Isolates were sampled and identified on the basis morphology and phylogeny, through analysis of a partial translation elongation factor 1- $\alpha$ sequence, ribosomal DNA internal transcribed spacers, and $\beta$-tubulin gene sequence. Ten taxa were identified, namely, Lasiodiplodia brasiliense, L. euphorbicola, L. gonubiensis, L. iraniensis, L. jatrophicola, L. gravistriata sp. nov., L. pseudotheobromae, L. theobromae, Neofusicoccum batangarum, and Pseudofusicoccum stromaticum. Lasiodiplodia theobromae has been previously reported in cashew and is the most prevalent species observed. All the other species are reported here for the first time on this host. All species of Botryosphaeriaceae were pathogenic on detached green cashew shoots. Differences in aggressiveness were observed among the species, with N. batangarum, L. iraniensis, L. jatrophicola, and L. gravistriata characterized as the most aggressive species, whilst L. euphorbicola and L. pseudotheobromae were identified as the least aggressive.
\end{abstract}

(c) 2016 British Mycological Society. Published by Elsevier Ltd. All rights reserved.

\footnotetext{
* Corresponding author. Tel.: +55 813320 6209; fax: +55 8133206201.

E-mail address: marcos.camara@ufrpe.br (M. P. S. Câmara).
}

http://dx.doi.org/10.1016/j.funbio.2016.07.006

1878-6146/৫ 2016 British Mycological Society. Published by Elsevier Ltd. All rights reserved. 


\section{Introduction}

Cashew (Anacardium occidentale) is a tropical evergreen crop cultivated worldwide with a centre of origin in the Amazonian forest of Brazil. In contrast to the other seven species within the genus Anacardium, only cashew (A. occidentale) is an economically important nut crop, with both an edible hypo carp (apple) and nutritious kernel arising from a drupe (Aliyu 2012). It is important as an export commodity, with considerable consumption in Europe and the USA. Brazilian production in 2013 reached $259900 \mathrm{t}$, from a production area of $708430 \mathrm{ha}$. In 2016, 12165 t of cashew nuts were exported generating about US\$ $79 \mathrm{M}$. The north-eastern region of Brazil is responsible for $99 \%$ of the country's production (Agrianual 2015), with the cashew industry in rural areas recognized to be of considerable socio-economic importance (Moreira et al. 2013).

Of the numerous diseases that compromise cashew production, cashew gummosis, which is caused by Lasiodiplodia theobromae, is considered one of the most important diseases for the cashew industry (Cysne et al. 2010). This fungal species was first reported on cashew in 1990 (Freire 1991), and was soon recognized as one of the most important diseases of the crop in north-eastern Brazil (Freire et al. 2002; Moreira et al. 2013). The main symptoms of this disease comprise the appearance of cankers along the trunk or branches, which develop over time and release a characteristic resin-like gum. Gummosis subsequently results in reduced water and nutrient transport, branch dieback, inflorescence blight, reduction in photosynthesis, and eventual plant death (Freire et al. 2002; Moreira et al. 2013).

To date only L. theobromae has been found associated with cashew gummosis (Freire et al. 2002; Cardoso et al. 2004; Muniz et al. 2012; Moreira et al. 2013). However, identification of causal agents was based on analysis of fungal morphology and cultural characteristics, which are today considered insufficient for species identification in the genus Lasiodiplodia (Phillips et al. 2013).

Lasiodiplodia is a member genus of the Botryosphaeriaceae, a family in the Dothideomycetes. This family contains numerous fungal species which occur as saprophytes, parasites or endophytes on a diverse range of plant hosts (Slippers \& Wingfield 2007; Phillips et al. 2013). In addition to cashew in Brazil, genera of Botryosphaeriaceae such as Botryosphaeria, Fusicoccum, Macrophomina, Neofusicoccum, Neoscytalidium, and Pseudofusicoccum (Marques et al. 2013b; Machado et al. 2014) have been reported to cause disease in several other economically important crops including avocado (Persea americana), banana (Musa spp.), barbados cherry (Malpighia glabra), cacao (Theobromae cacao), castor bean (Ricinus communis), citrus (Citrus spp.), coconut palm (Cocos nucifera), custard apple (Annona squamosa), grapevine and table grape (Vitis spp.), guaraná (Paullinia cupana), guava (Psidium guajava), mango (Mangifera indica), muskmelon (Cucumis melo), papaya (Carica papaya), passion fruit (Passiflora edulis), physic nut (Jatropha curcas), sour sop (Annona muricata), and watermelon (Citrullus lanatus) (Costa et al. 2010; Marques et al. 2013a; Machado et al. 2014; Netto et al. 2014; Correia et al. 2016).

Although the taxonomy of the Botryosphaeriaceae has until recently been based upon morphology of asexual morphs, more recent phylogenetic inference based upon analysis of sequence data for target DNA loci has had considerable impact on the systematics of the Botryosphaeriaceae, with increased resolution enabling discrimination of species with overlapping morphological characteristics (de Wet et al. 2008; Phillips et al. 2013).

Despite the pathogenic importance attributed to Botryosphaeriaceae on diverse host plants, there have been no phylogenetic analyses of this family on cashew. Given the increasing economic importance of cashew gummosis and the recent reports of new species of Botryosphaeriaceae occurring on tropical plants, it is possible that a number of species of this family may be associated with cashew gummosis in Brazil. For effective disease management, a clear understanding of disease aetiology is essential for determination of the distribution of individual species and their disease epidemiology. In this context, the objectives of this study were (i) to identify species of Botryosphaeriaceae associated with cashew gummosis in Brazil, (ii) to determine the prevalence and distribution of each species, and (iii) to characterize isolates in terms pathogenicity and virulence using excised cashew green shoots.

\section{Materials and methods}

\section{Isolation of fungal material}

During 2013 and 2014, samples were obtained from 30 Anacardium orchards, located in six states of Brazil (Alagoas, Ceará, Minas Gerais, Pernambuco, Piauí, and Rio Grande do Norte). In each orchard, a total of 15 Anacardium trees exhibiting gummosis symptoms were selected for isolation of fungal material. Symptomatic shoot material at the interface between necrotic and apparently uninfected tissue was surface sterilized using $70 \%$ ethanol for $30 \mathrm{~s}$ followed by $1 \% \mathrm{NaOCl}$ for $1 \mathrm{~min}$. Following rinsing once with sterile distilled water for $30 \mathrm{~s}$, material was then dried and 4-5 mm fragments plated onto potato dextrose agar (PDA) (Acumedia, Lansing, USA) containing $0.5 \mathrm{~g} \mathrm{l}^{-1}$ streptomycin sulphate (PDAS). Following incubation at $25^{\circ} \mathrm{C}$ in the dark for a period of 3-4 d, all colonies showing morphological characteristic typical of the Botryosphaeriaceae (Sutton 1980; Phillips 2006) were plated onto PDA and incubated at $25{ }^{\circ} \mathrm{C}$ in the dark and observed over a period $15 \mathrm{~d}$. Pycnidial production was induced following growth on $2 \%$ water agar (WA) and autoclaved pine needles (PNA) as carbon source. After a 3-week incubation period at $25^{\circ} \mathrm{C}$ under a $12 \mathrm{~h}$ daily photoperiod with near-ultraviolet light (Slippers et al. 2004a), individual pycnidia were from each isolate were examined under a stereo-microscope (Zeiss Stemi DV4; Carl Zeiss, Berlin, Germany), and transferred in $250 \mu \mathrm{l}$ of sterile distilled water. A $20 \mu \mathrm{l}$ aliquot of the resultant conidial suspension was spread onto PDAS and incubated at $28^{\circ} \mathrm{C}$ in the dark for $24 \mathrm{~h}$. Single spore isolates were prepared for each sample through transfer onto fresh PDA plates. Based upon morphological characteristics typical of the genus, a total of 138 isolates were identified as members of the Botryosphaeriaceae. All isolates were preserved on PDA slants at $5{ }^{\circ} \mathrm{C}$ in the dark. 


\section{Molecular-based amplification}

For identification of the Botryosphaeriaceae, a region of the translation elongation factor $1 \alpha(E F 1-\alpha)$ gene was amplified and sequenced for all isolates collected from the cashew orchards. The rDNA internal transcribed spacer (ITS) regions was employed to support species identity based on EF1$\alpha$ gene sequence data, with a portion of the $\beta$-tubulin gene for the fusicoccum-like representative isolates. Total DNA was extracted from aerial mycelium from 7-day-old cultures grown on PDA at $25^{\circ} \mathrm{C}$ using an AxyPrep ${ }^{\text {TM }}$ Multisource Genomic DNA Miniprep Kit (Axygen Scientific Inc., Union City, USA) according to the manufacturer's instructions.

The target region of the EF1- $\alpha$ gene was amplified using primer pairs EF-688F and EF-1251R (Alves et al. 2008), as described by Phillips et al. (2005). The rDNA ITS region was amplified using universal primers ITS1 and ITS4 (White et al. 1990) according to Slippers et al. (2004b). A portion of the $\beta$-tubulin (TUB) gene was amplified using the primers BT2a and BT2b (Glass \& Donaldson 1995). Each PCR reaction contained $1 \mu \mathrm{l}$ of total DNA, $1.5 \mu \mathrm{M}$ of each primer, $25 \mu \mathrm{l}$ of $2 \times$ PCR Master Mix (Thermo Scientific, Waltham, USA), containing $0.05 \mathrm{U}$ of Taq DNA polymerase, $2 \times$ reaction buffer, $4 \mathrm{mM} \mathrm{MgCl}_{2}$, and $0.4 \mathrm{mM}$ dNTPs. Reaction volumes were completed to $50 \mu \mathrm{l}$ volumes using PCR-grade water. Temperature cycling was conducted with a thermo cycler (Biocycler MJ 96; Applied Biosystems, Foster City, USA). PCR products were photodocumented under UV light after staining $1.5 \%$ agarose gels with ethidium bromide $\left(0.5 \mu \mathrm{g} \mathrm{ml}^{-1}\right)$ for $1 \mathrm{~min}$. Purification of PCR products was performed with the AxyPrep ${ }^{\mathrm{TM}}$ PCR Cleanup Kit (Axygen), according to the manufacturer's instructions. The rDNA ITS, EF1- $\alpha$, and $\beta$-tubulin regions were forward and reverse sequenced with an ABI 3730 XL DNA Analyzer (Applied Biosystems).

\section{Phylogenetic analyses}

Alignment of sequence data was conducted using ClustalX v. 1.83 (Thompson et al. 1997), with the following parameters: pair wise alignment (gap opening $=10$, gap extension $=0.1$ ); multiple alignment (gap opening $=10$, gap extension $=0.2$, transition weight $=0.5$, delay divergent sequences $=25 \%$ ). Sequences of two isolates of each species of Botryosphaeriaceae including the type strains available in GenBank were also included in the analyses and outgroup (Table 1). Only the type species of Lasiodiplodia pontae was included in the analysis because the two other strain available [isolate IBL 14 (GenBank accession number: ITS-KT151795; EF-1 $\alpha$-KT151792) and isolate IBL 18 (GenBank accession number: ITS-151796; EF-1 $\alpha$ KT151793)] did not cluster in the type strain clade (Coutinho et al. 2016). Simple indel coding, as implemented by GapCoder (Young \& Healy 2003), was employed for incorporation of phylogenetic information present in indels (gaps) into the phylogenetic analyses. Tree robustness was evaluated following 1000 bootstrap replications (Hillis \& Bull 1993). Sequence alignments were deposited in TreeBASE (http://www.treebase.org/) under accession number S19242 for Lasiodiplodia, S19243 for Neofusicoccum, and S19241 for Pseudofusicoccum. Phylogenetic analyses were conducted using the programme GENEIOUS v. 7.1.8 (Kearse et al. 2012). Maximum likelihood estimation was conducted using a plugin for PhyML (Guindon et al. 2010) and Bayesian analyses using MrBayes v. 3.0b4 (Ronquist \& Huelsenbeck 2003). Bayesian analysis was performed by four independent runs with the Markov Chain Monte Carlo (MCMC) algorithms (Larget \& Simon 1999). Data were partitioned according to locus, with nucleotide substitution model parameters for each partition set as described below. Four parallel MCMC chains were run, with a heating scheme set at 0.3, under a general time-reversible (GTR) substitution model with rate variation of gamma-distribution (G), and proportion of invariable site (I) (Rodríguez et al. 1990). Trees were sampled every 1000th generation from a total of 10000 trees, with the first 2500 trees discarded as representing the burn-in phase of each analysis. The remaining 7500 trees (stationary distribution) were employed for determination of posterior probabilities (Rannala \& Yang 1996) and mapping onto the majority-rule consensus tree. FigTree v.1.4.2 (Rambaut 2009) was employed for tree visualization. Representative cultures of the species identified in this study were deposited in the Culture Collection of Phytopathogenic Fungi 'Prof. Maria Menezes' (CMM) at the Universidade Federal Rural de Pernambuco, Brazil.

\section{Morphology and cultural characteristics}

Colony morphology and conidial characteristics were examined for a total of 33 representative isolates among the Botryosphaeriaceae species identified following phylogenetic analysis. Colony colour and aerial hyphae were recorded after $15 \mathrm{~d}$ of growth on $2 \%$ malt extract agar (MEA) (Acumedia) at $25^{\circ} \mathrm{C}$ in the dark. Colony colours were examined according to Rayner (1970). Conidial morphology characteristics were examined after growth under near-ultraviolet light on PNA, as previously described. Digital images for conidia and other structures mounted in $100 \%$ lactic acid were recorded using a Leica DFC320 camera fitted to a Leica DMR HC microscope with Nomarski differential interference contrast optics (Leica Microsystems Imaging Solutions Ltd., Cambridge, UK). The Leica IM500 measurement module was employed to determine the length and width of 50 conidia per isolate, with mean values and standard errors calculated for all measurements. Conidial shape, colour, and septation were also recorded.

The effect of temperature on colony growth was examined across the different species identified. Four replicates were included per isolate, with experiments performed in duplicate. Mycelial plugs isolated from the growing margin of 3-dayold colonized plates were transferred onto $2 \%$ MEA plates and incubation the dark at temperatures ranging from $5{ }^{\circ} \mathrm{C}$ to $35^{\circ} \mathrm{C}$, with $5{ }^{\circ} \mathrm{C}$ intervals. After a 2-day period, colony diameters $(\mathrm{mm})$ were measured in two perpendicular directions. Mycelial growth rate $\left(\mathrm{mm} \mathrm{d}^{-1}\right)$ was estimated based on colony diameters following growth at $30^{\circ} \mathrm{C}$. In order to estimate the optimal growth temperature, recorded colony diameters were plotted against temperature and a curve fitted through cubic polynomial regression $(y=a+b x+c x 2+d x 3)$ using the programme TableCurve ${ }^{\text {TM }}$ 2D v. 5.01 (SYSTAT Software Inc., Chicago, USA). One-way analyses of variance (ANOVA) were conducted on optimum temperature and mycelia growth rate data, with means for each species compared with Fisher's least significant difference (LSD) test at the $5 \%$ 
Table 1 - Isolates of Botryosphaeriaceae species used in this study.

\begin{tabular}{|c|c|c|c|c|c|c|c|}
\hline \multirow[t]{2}{*}{ Taxon } & \multirow[t]{2}{*}{ Isolate code $\mathrm{e}^{\mathrm{a}}$} & \multirow[t]{2}{*}{ Host } & \multirow[t]{2}{*}{ Location } & \multirow[t]{2}{*}{ Collector } & \multicolumn{3}{|c|}{ GenBank Accession No. ${ }^{b}$} \\
\hline & & & & & ITS & EF1- $\alpha$ & $\beta$-tubulin \\
\hline $\begin{array}{l}\text { Botryosphaeria } \\
\text { dothidea }\end{array}$ & CMW 8000 & Prunus sp. & Switzerland & B. Slippers & AY236949 & AY236898 & \\
\hline B. dothidea & CBS $110302^{*}$ & Vitis vinifera & Portugal & A. J. L. Phillips & AY259092 & AY573218 & \\
\hline Diplodia mutila & CBS 136015 & Populus alba & Portugal & A. Alves & KJ361838 & KJ361830 & \\
\hline D. seriata & CBS $112555^{*}$ & Vitis vinifera & Portugal & A.J.L. Phillips & AY259094 & AY573220 & \\
\hline $\begin{array}{l}\text { Lasiodiplodia } \\
\text { brasiliense }\end{array}$ & CMM 4011 & Mangifera indica & Brazil & M.W. Marques & $\mathrm{JX} 464074$ & $\mathrm{JX} 464037$ & \\
\hline L. brasiliense & CMM 4015* & Mangifera indica & Brazil & M.W. Marques & JX464063 & JX464049 & \\
\hline L. brasiliense & CMM 4469 & $\begin{array}{l}\text { Anacardium } \\
\text { occidentale }\end{array}$ & Brazil & M.S.B. Netto & KT325574 & KT325580 & \\
\hline L. brasiliense & CMM 4470 & $\begin{array}{l}\text { Anacardium } \\
\text { occidentale }\end{array}$ & Brazil & M.S.B. Netto & KT325575 & KT325579 & \\
\hline L. caatinguensis & CMM 1325 & Citrus sinensis & Brazil & I.B.L. Coutinho \& J.S. Lima & KT154760 & КT008006 & \\
\hline L. caatinguensis & IBL 40 & Spondias purpurea & Brazil & J.S. Lima \& J.E. Cardoso & KT154762 & KT154755 & \\
\hline L. citricola & CBS $124707^{*}$ & Citrus sp. & Iran & $\begin{array}{l}\text { J. Abdollahzadeh \& } \\
\text { A. Javadi }\end{array}$ & GU945354 & GU945340 & \\
\hline L. citricola & CBS 124706 & Citrus sp. & Iran & $\begin{array}{l}\text { J. Abdollahzadeh \& } \\
\text { A. Javadi }\end{array}$ & GU945353 & GU945339 & \\
\hline L. crassispora & CMW 13448 & $\begin{array}{l}\text { Eucalyptus } \\
\text { urophylla }\end{array}$ & Venezuela & S. Mohali & DQ103552 & DQ103559 & \\
\hline L. crassispora & WAC 12533* & Santalum album & Australia & T.I. Burgess/B. Dell & DQ103550 & DQ103557 & \\
\hline L. egyptiacae & CBS $130992^{*}$ & Mangifera indica & Egypt & A.M. Ismail & JN814397 & JN814424 & \\
\hline L. egyptiacae & BOT-29 & Mangifera indica & Egypt & A.M. Ismail & JN814401 & JN814428 & \\
\hline L. euphorbicola & CMM 3651 & Jatropha curcas & Brazil & $\begin{array}{l}\text { A.R. Machado \& } \\
\text { O.L. Pereira }\end{array}$ & KF234553 & KF226711 & \\
\hline L. euphorbicola & CMM 3609* & Jatropha curcas & Brazil & $\begin{array}{l}\text { A.R. Machado \& } \\
\text { O.L. Pereira }\end{array}$ & KF234543 & KF226689 & \\
\hline L. euphorbicola & CMM 3652 & Jatropha curcas & Brazil & $\begin{array}{l}\text { A.R. Machado \& } \\
\text { O.L. Pereira }\end{array}$ & KF234554 & KF226715 & \\
\hline L. euphorbicola & CMM 4473 & Anacardium humile & Brazil & M.S.B. Netto & KT325568 & КT325581 & \\
\hline L. exigua & CBS $137785^{*}$ & Retama raetam & Tunisia & B.T. Linaldeddu & KJ638317 & KJ638336 & \\
\hline L. exigua & BL 184 & Retama raetam & Tunisia & B.T. Linaldeddu & KJ638318 & KJ638337 & \\
\hline L. gilaniensis & CBS $124704^{*}$ & Unknown & Iran & $\begin{array}{l}\text { J. Abdollahzadeh \& } \\
\text { A. Javadi }\end{array}$ & GU945351 & GU945342 & \\
\hline L. gilaniensis & CBS 124705 & Unknown & Iran & $\begin{array}{l}\text { J. Abdollahzadeh \& } \\
\text { A. Javadi }\end{array}$ & GU945352 & GU945341 & \\
\hline L. gonubiensis & CBS $115812^{*}$ & Syzigium cordatum & South Africa & D. Pavlic & AY639595 & DQ103566 & \\
\hline L. gonubiensis & CBS 116355 & Syzigium cordatum & South Africa & D. Pavlic & AY639594 & DQ103567 & \\
\hline L. gonubiensis & CMM 4468 & Anacardium humile & Brazil & M.S.B. Netto & KT325571 & KT325584 & \\
\hline L. gravistriata & CMM 4564* & Anacardium humile & Brazil & M.S.B. Netto & KT250949 & KT250950 & \\
\hline L. gravistriata & CMM 4565 & Anacardium humile & Brazil & M.S.B. Netto & КT250947 & KT266812 & \\
\hline L. gravistriata & CMM 4566 & Anacardium humile & Brazil & M.S.B. Netto & KT250946 & KT266813 & \\
\hline L. gravistriata & CMM 4570 & Anacardium humile & Brazil & M.S.B. Netto & KT250948 & KT266814 & \\
\hline L. hormozganensis & CBS $124709^{*}$ & Olea sp. & Iran & $\begin{array}{l}\text { J. Abdollahzadeh \& } \\
\text { A. Javadi }\end{array}$ & GU945355 & GU945343 & \\
\hline L. hormozganensis & CBS 124708 & Mangifera indica & Iran & $\begin{array}{l}\text { J. Abdollahzadeh \& } \\
\text { A. Javadi }\end{array}$ & GU945356 & GU945344 & \\
\hline L. iraniensis & CBS $124710^{*}$ & Mangifera indica & Iran & N. Khezrinejad & GU945346 & GU945334 & \\
\hline L. iraniensis & CBS 124711 & Juglans sp. & Iran & A. Javadi & GU943447 & GU945335 & \\
\hline L. iraniensis & CMM 4557 & Anacardium occidentale & Brazil & M.S.B. Netto & КT325573 & КT325586 & \\
\hline L. iraniensis & CMM 4559 & Anacardium occidentale & Brazil & M.S.B. Netto & KT325572 & КT325585 & \\
\hline L. jatrophicola & CMM $3610^{*}$ & Jatropha curcas & Brazil & $\begin{array}{l}\text { A.R. Machado \& } \\
\text { O.L. Pereira }\end{array}$ & KF234544 & KF226690 & \\
\hline L. jatrophicola & CMM 0247 & V. vinifera & Brazil & M. A. Silva & KJ417895 & KJ417870 & \\
\hline L. jatrophicola & CMM 4471 & Anacardium occidentale & Brazil & M.S.B. Netto & KT325569 & KT325582 & \\
\hline L. jatrophicola & CMM 4472 & Anacardium occidentale & Brazil & M.S.B. Netto & КT325570 & КT325583 & \\
\hline L. macrospora & CMM $3833^{*}$ & Jatropha curcas & Brazil & $\begin{array}{l}\text { A.R. Machado \& } \\
\text { O.L. Pereira }\end{array}$ & KF234557 & KF226718 & \\
\hline L. mahajangana & CBS $124927^{*}$ & Terminalia catappa & Madagascar & J. Roux & FJ900597 & FJ900643 & \\
\hline L. mahajangana & CBS 124925 & Terminalia catappa & Madagascar & J. Roux & FJ900595 & FJ900641 & \\
\hline L. margaritaceae & CBS $122519^{*}$ & Adansonia gibbosa & Australia & T.I. Burgess & EU144050 & EU144065 & \\
\hline L. margaritaceae & CBS 122065 & Adansonia gibbosa & Australia & T.I. Burgess & EU144051 & EU144066 & \\
\hline L. mediterranea & CBS $137783^{*}$ & Quercus ilex & Italy & B.T. Linaldeddu & KJ638312 & KJ638331 & \\
\hline
\end{tabular}


Table 1 - (continued)

\begin{tabular}{|c|c|c|c|c|c|c|c|}
\hline \multirow[t]{2}{*}{ Taxon } & \multirow[t]{2}{*}{ Isolate code ${ }^{a}$} & \multirow[t]{2}{*}{ Host } & \multirow[t]{2}{*}{ Location } & \multirow[t]{2}{*}{ Collector } & \multicolumn{3}{|c|}{ GenBank Accession No. } \\
\hline & & & & & ITS & EF1- $\alpha$ & $\beta$-tubulin \\
\hline L. mediterranea & CBS 137784 & Vitis vinifera & Italy & S. Serra & KJ638311 & KJ638330 & \\
\hline L. mediterranea & ALG 36 & Citrus sinensis & Algeria & A. Berraf-Tebbal & KJ638314 & KJ638333 & \\
\hline L. missouriana & CBS $128311^{*}$ & Vitis sp. & Missouri, USA & K. Striegler \& G.M. Leavitt & HQ288225 & HQ288267 & \\
\hline L. missouriana & CBS 128312 & Vitis sp. & Missouri, USA & K. Striegler \& G.M. Leavitt & HQ288226 & HQ288268 & \\
\hline L. parva & CBS $45678^{*}$ & Cassava-field soil & Colombia & O. Rangel & EF622083 & EF622063 & \\
\hline L. parva & CBS 49578 & Cassava-field soil & Colombia & O. Rangel & EF622084 & EF622064 & \\
\hline L. plurivora & CBS $120832^{*}$ & Prunus salicina & South Africa & U. Damm & EF445362 & EF445395 & \\
\hline L. pontae & CMM1277 & Spondias purpurea & Brazil & J.S. Lima \& F.C.O. Freire & KT151794 & KT151791 & \\
\hline L. pseudotheobromae & CBS $116459^{*}$ & Gmelina arborea & Costa Rica & J. Carranza-Velásquez & EF622077 & EF622057 & \\
\hline L. pseudotheobromae & IRAN1518C & Citrus sp. & Iran & $\begin{array}{l}\text { J. Abdollahzadeh \& } \\
\text { A. Javadi }\end{array}$ & GU973874 & GU973866 & \\
\hline L. pseudotheobromae & CMM 4474 & Anacardium humile & Brazil & M.S.B. Netto & KT728914 & KT882611 & \\
\hline L. pseudotheobromae & CMM 4475 & Anacardium humile & Brazil & M.S.B. Netto & KT728915 & KT882612 & \\
\hline L. pyriformis & CMW 25414* & Acacia mellifera & Namibia & $\begin{array}{l}\text { F.J.J. van der Walt \& } \\
\text { J. Roux }\end{array}$ & EU101307 & EU101352 & \\
\hline L. pyriformis & CMW 25415 & Acacia mellifera & Namibia & $\begin{array}{l}\text { F.J.J. van der Walt \& } \\
\text { J. Roux }\end{array}$ & EU101308 & EU101353 & \\
\hline L. rubropurpurea & CBS $118740^{*}$ & Eucalyptus grandis & Australia & T.I. Burgess/G. Pegg & DQ103553 & EU673304 & \\
\hline L. rubropurpurea & WAC 12536 & Eucalyptus grandis & Australia & T.I. Burgess/G. Pegg & DQ103554 & DQ103572 & \\
\hline L. subglobosa & CMM 3872* & Jatropha curcas & Brazil & $\begin{array}{l}\text { A.R. Machado \& } \\
\text { O.L. Pereira }\end{array}$ & KF234558 & KF226721 & \\
\hline L. subglobosa & CMM 4046 & Jatropha curcas & Brazil & $\begin{array}{l}\text { A.R. Machado \& } \\
\text { O.L. Pereira }\end{array}$ & KF234560 & KF226723 & \\
\hline Lasiodiplodia sp. & CPC 22800 & Mangifera indica & Thailand & T. Trakunyingcharoen & KJ193643 & KJ193687 & \\
\hline L. thailandica & CPC 22755 & Phyllanthus acidus & Thailand & T. Trakunyingcharoen & KM00633 & KM006464 & \\
\hline L. thailandica & CPC 22795 & Mangifera indica & Thailand & T. Trakunyingcharoen & KJ19367 & KJ193681 & \\
\hline L. theobromae & CBS $16496^{*}$ & $\begin{array}{l}\text { Fruit along coral } \\
\text { reef coast }\end{array}$ & New Guinea & A. Aptroot & AY64025 & AY640258 & \\
\hline L. theobromae & CMM 0310 & Vitis vinifera & Brazil & M. A. Silva & KJ41790 & KJ417880 & \\
\hline L. theobromae & CMM 0384 & Vitis vinifera & Brazil & M. A. Silva & KJ417904 & KJ417876 & \\
\hline L. theobromae & CMM 2269 & Carica papaya & Brazil & J.H.A. Monteiro & KC484821 & KC481585 & \\
\hline L. theobromae & CMM 4499 & Anacardium occidentale & Brazil & M.S.B. Netto & KT325578 & KT325587 & \\
\hline L. theobromae & CMM 4508 & Anacardium occidentale & Brazil & M.S.B. Netto & KT325576 & КT325588 & \\
\hline L. theobromae & CMM 4513 & Anacardium occidentale & Brazil & M.S.B. Netto & KT325577 & KT325589 & \\
\hline L. venezuelensis & CBS $118739^{*}$ & Acacia mangium & Venezuela & S. Mohali & DQ103547 & DQ103568 & \\
\hline L. venezuelensis & WAC 12540 & Acacia mangium & Venezuela & S. Mohali & DQ103548 & DQ103569 & \\
\hline L. viticola & CBS 128313 & Vitis vinifera & USA & $\begin{array}{l}\text { R.D. Cartwright \& } \\
\text { W.D. Gubler }\end{array}$ & HQ288227 & HQ288269 & \\
\hline L. viticola & UCD 2604MO & Vitis vinifera & USA & K. Striegler \& W.D. Gubler & HQ288228 & HQ288270 & \\
\hline $\begin{array}{l}\text { Neofusicoccum } \\
\text { batangarum }\end{array}$ & CBS $124924^{*}$ & Terminalia catappa & Africa & D. Begoude/J. Roux & FJ900607 & FJ900653 & FJ900615 \\
\hline N. batangarum & CBS 124923 & Terminalia catappa & Africa & D. Begoude/J. Roux & FJ900608 & FJ800654 & FJ900616 \\
\hline N. batangarum & CMM 4547 & Anacardium othonianum & Brazil & M.S.B. Netto & KT728916 & KT728920 & KT728912 \\
\hline N. batangarum & CMM 4553 & Anacardium othonianum & Brazil & M.S.B. Netto & KT728917 & KT728921 & KT728913 \\
\hline N. brasiliense & CMM $1269^{*}$ & Mangifera indica & Brazil & M.W. Marques & JX513629 & JX513609 & KC794932 \\
\hline N. brasiliense & CMM 1285 & Mangifera indica & Brazil & M. W. Marques & JX513628 & JX513608 & KC794030 \\
\hline N. cordaticola & CBS $123634^{*}$ & Syzigium cordatum & South Africa & D. Pavlic & EU821898 & EU821868 & EU821838 \\
\hline N. cordaticola & CBS 123635 & Syzigium cordatum & South Africa & D. Pavlic & EU821903 & EU821843 & EU821843 \\
\hline N. kwambonambiense & CBS 123639* & Eucalyptus grandis & South Africa & D. Pavlic & EU821900 & EU821870 & EU821840 \\
\hline N. kwambonambiense & CBS 123641 & Eucalyptus grandis & South Africa & D. Pavlic & EU821949 & EU821889 & EU821859 \\
\hline N. macroclavatum & WAC $12445^{*}$ & Eucalyptus globulus & Australia & T.I. Burgess & DQ093197 & DQ093218 & DQ093207 \\
\hline N. macroclavatum & WAC 12446 & Eucalyptus globulus & Australia & T.I. Burgess & DQ093219 & DQ093219 & DQ093208 \\
\hline N. occulatum & CBS $128008^{*}$ & $\begin{array}{l}\text { Eucalyptus grandis } \\
\text { hybrid }\end{array}$ & Australia & T.I. Burgess & EU730103 & EU339509 & EU339472 \\
\hline N. occulatum & MUCC 296 & Eucalyptus pellita & Australia & T.I. Burgess & EU301034 & EU339512 & EU339475 \\
\hline N. parvum & PD 106 & Prunus dulcis & USA & T.J. Michailides & GU251139 & GU251271 & KC794029 \\
\hline N. parvum & ATCC 58189* & Malus sylvestris & New Zealand & G.J. Samuels & AF243395 & AY236883 & AY236912 \\
\hline N. ribis & CBS $12126^{*}$ & Ribis rubrum & USA & B. Slippers & AF241177 & AY236879 & AY236908 \\
\hline N. ribis & CMW 7772 & Ribis sp. & USA & B. Slippers \& G. Hudler & AY236925 & AY236877 & AY236906 \\
\hline N. umdonicola & CMW 14058* & Syzigium cordatum & South Africa & D. Pavlic & EU821934 & EU821874 & EU821844 \\
\hline N. umdonicola & CMW 14060 & Syzigium cordatum & South Africa & D. Pavlic & EU821935 & EU821875 & EU821845 \\
\hline
\end{tabular}


Table 1 - (continued)

\begin{tabular}{|c|c|c|c|c|c|c|c|}
\hline \multirow[t]{2}{*}{ Taxon } & \multirow[t]{2}{*}{ Isolate code ${ }^{a}$} & \multirow[t]{2}{*}{ Host } & \multirow[t]{2}{*}{ Location } & \multirow[t]{2}{*}{ Collector } & \multicolumn{3}{|c|}{ GenBank Accession No. ${ }^{b}$} \\
\hline & & & & & ITS & EF1- $\alpha$ & $\beta$-tubulin \\
\hline $\begin{array}{l}\text { Pseudofusicoccum } \\
\text { adansoniae }\end{array}$ & CBS $122054^{*}$ & Eucalyptus sp. & Australia & D. Pavlic & EF585532 & EF585570 & \\
\hline P. adansoniae & WAC 13299 & Mangifera indica & Australia & J. Ray & GU172404 & GU172436 & \\
\hline P. ardesiacum & CBS $122062^{*}$ & Adansonia gibbosa & Australia & D. Pavlic & EU144060 & EU144075 & \\
\hline P. ardesiacum & WAC 13294 & Mangifera indica & Australia & J. Ray & GU172405 & GU172437 & \\
\hline P. artocarpi & CPC 22796 & Artocarpus heterophyllus & Thailand & T. Trakunyingcharoen & KM006452 & KM006483 & \\
\hline P. kimberleyense & CBS $122061^{*}$ & Ficus opposita & Australia & D. Pavlic & EU144059 & EU144074 & \\
\hline P. kimberleyense & WAC 13293 & Mangifera indica & Australia & J. Ray & GU172406 & GU172438 & \\
\hline P. olivaceum & CBS $124939^{*}$ & Pterocarpus angolensis & Africa & J. Roux & FJ888459 & FJ888437 & \\
\hline P. olivaceum & CBS 124940 & Pterocarpus angolensis & Africa & J. Mehl \& J Roux & FJ888462 & FJ888438 & \\
\hline P. stromaticum & CMW 13435 & Eucalyptus hybrid & Venezuela & S. Mohali & DQ436935 & DQ436936 & \\
\hline P. stromaticum & CMW 13434* & Eucalyptus hybrid & Venezuela & S. Mohali & AY693974 & AY693975 & \\
\hline P. stromaticum & CMM 4541 & Anacardium othonianum & Brazil & M.S.B. Netto & KT728918 & KT728922 & \\
\hline P. stromaticum & CMM 4544 & Anacardium othonianum & Brazil & M.S.B. Netto & KT728919 & KT728923 & \\
\hline P. violaceum & CBS $124936^{*}$ & Pterocarpus angolensis & Africa & J. Mehl \& J Roux & FJ888474 & FJ888442 & \\
\hline P. violaceum & CBS 124937 & Pterocarpus angolensis & Africa & J. Roux & FJ888458 & FJ888440 & \\
\hline \multicolumn{8}{|c|}{$\begin{array}{l}\text { a ALG = A. Berraf-Tebbal, Université Saad Dahleb, Blida, Algeria; ATCC = American Type Culture Collection, Manassas, USA; BL=B.T. Linal- } \\
\text { deddu, Università degli Studi di Sassari, Sassari, Italy; BOT = A. M. Ismail, Plant Pathology Research Institute, Giza, Egypt; } \\
\text { CBS = Centraalbureau voor Schimmelcultures Utrecht, Netherlands; CMM = Culture Collection of Phytopathogenic Fungi 'Prof. Maria Menezes', } \\
\text { Universidade Federal Rural de Pernambuco, Recife, Brazil; CMW = Forestry and Agricultural Biotechnology Institute, University of Pretoria, Pre- } \\
\text { toria, South Africa; CPC = Culture Collection of P.W. Crous, housed at CBS; MUCC = Murdoch University Culture Collection, Perth, Australia; } \\
\text { IRAN = Culture Collection of the Iranian Research Institute of Plant Protection, Tehran, Iran; PD = Culture Collection, University of California, } \\
\text { Davis, USA; STE-U = Culture Collection of the Department of Plant Pathology, University of Stellenbosch, South Africa; UCD = Phaff Yeast Cul- } \\
\text { ture Collection, Department of Food Science and Technology, University of California, Davis, USA; WAC = Department of Agriculture Western } \\
\text { Australia Plant Pathogen Collection, Perth, Australia. }{ }^{*} \text { ex-type or ex-epitype. b Sequences derived in this study are emphasized in bold. }\end{array}$} \\
\hline
\end{tabular}

significance level using STATISTIX v. 9.0 (Analytical Software, Tallahassee, USA).

\section{Pathogenicity and aggressiveness assays}

Pathogenicity and aggressiveness of all Botryosphaeriaceae isolates characterized morphologically were examined using detached green shoots of Anacardium occidentale (cv. BRS 274) (Amponsahet et al. 2011; Correia et al. 2016). Healthy $30 \mathrm{~cm} \mathrm{sec-}$ tions of soft green shoots were obtained from cashew trees (cv. BRS 274) from a non-commercial orchard at the Universidade Federal Rural de Pernambuco where Botryosphaeriaceae species were considered absent, based upon extensive sampling. The cut ends were firstly dipped in wax then cut in the centre of each shoot using a sterilized scalpel. Each superficial wound ( 4-mm length, 2-mm deep) was inoculated with a $4 \mathrm{~mm}$ diameter mycelial plug taken from the growing margin of a 5-day-old PDA culture of each isolate. As negative control checks, non-colonized PDA plugs were used for inoculation of shoots. In order to prevent drying, all inoculated areas were covered with Parafilm (Pechiney Co., Chicago, USA). Shoots were then incubated in a growth chamber for a $10 \mathrm{~d}$ period at $25^{\circ} \mathrm{C}$ and 12 -h photoperiod. Following incubation, Parafilm was removed and shoots were sliced lengthwise to enable visual observation of internal lesions. The presence of lesions advancing beyond the original 4-mm diameter inoculation point was considered indicative of pathogenicity. Isolate virulence was evaluated through accurate digital calliperbased (Mitutoyo Co., Kanagawa, Japan) measurement of lesions dimensions. The entire experiment was arranged in a completely randomized design, with four replicates employed per treatment (isolate) and one shoot per replicate. The entire experiment was conducted in duplicate. Differences in virulence were determined by analysis of data with a one-way ANOVA, with means compared by LSD test at the $5 \%$ significance level using the program STATISTIX.

\section{Results}

\section{Phylogenetic analyses}

Sampling from Anacardium spp. from numerous growing regions in Brazil (Fig 1) resulted in isolation of 138 isolates of Botryosphaeriaceae. Phylogenetic analysis of the EF1- $\alpha$ gene was employed for identification of all isolates, with rDNA ITS sequences analysed for 17 isolates that represented EF1- $\alpha$ haplotypes, and partial TUB gene sequences for six fusicoccumlike isolates. The GenBank accession numbers are listed in Table 1. Analysed EF1- $\alpha$ and TUB sequences were approximately 450 bp in size, while rDNA ITS sequences were approximately $580 \mathrm{bp}$ in size. The EF1- $\alpha$ and rDNA ITS sequences were combined in separate datasets, which corresponded to Lasiodiplodia species and Pseudofusicoccum species. The ITS, EF1- $\alpha$, and TUB sequences were combined in a third dataset corresponding to Neofusicoccum species. Datasets were analysed separately, resulting in three phylogenetic trees, one for each genus (Figs 2-4). The isolates obtained in this study grouped into 10 distinct clades. The combined EF1- $\alpha$ and rDNA ITS sequences for Lasiodiplodia contained data for 78 isolates, including two outgroup taxa. Out of a total of 1393 characters, 1136 


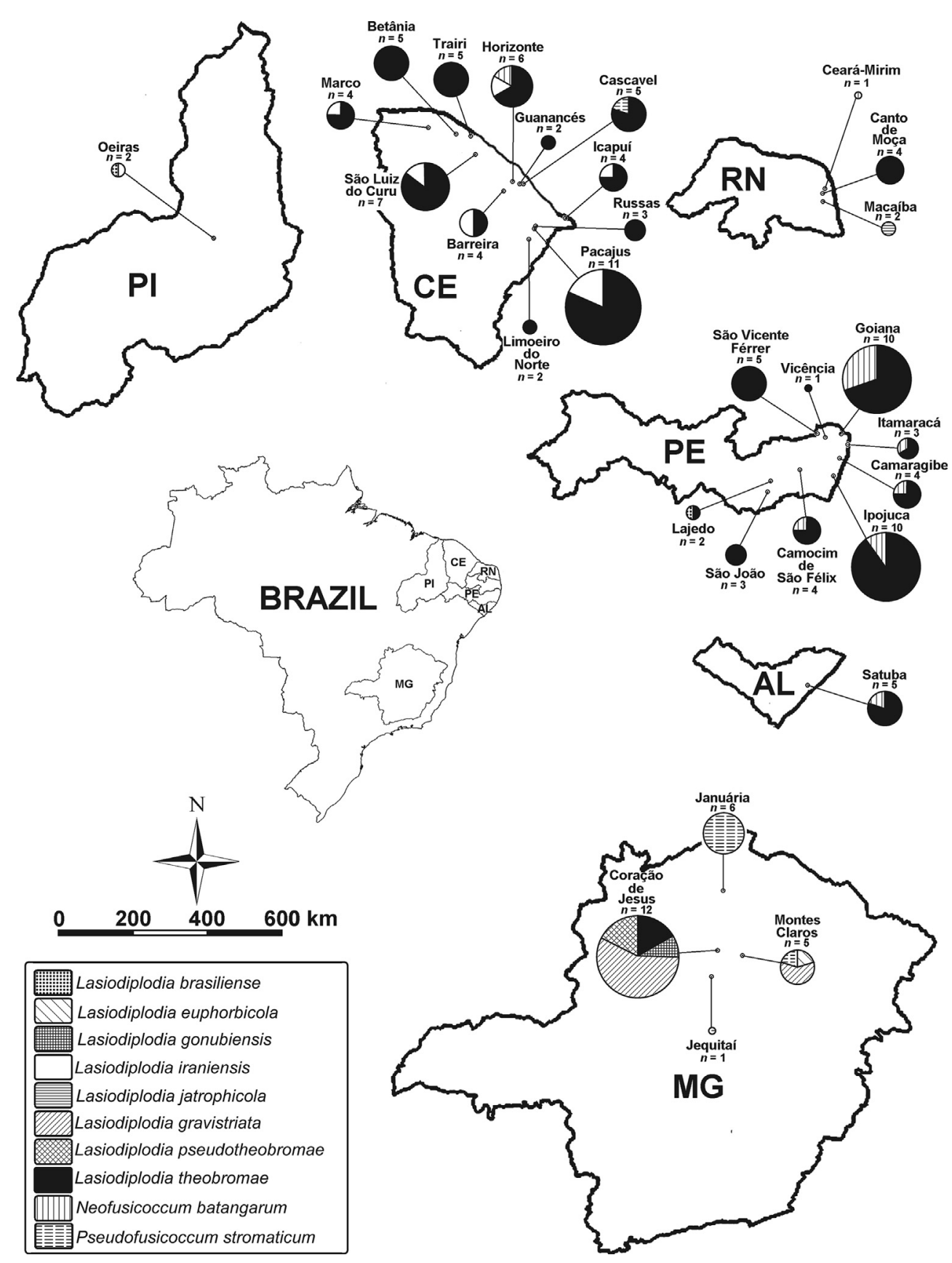

Fig 1 - Collection sites of Botryosphaeriaceae isolates associated with gummosis of Anacardium in seven different states of Brazil. Circles represent association frequency of each species with plants exhibiting symptoms of gummosis in each orchard sampled, $n$ is the number of isolates analysed in each orchard.

were constant, 231 were variable and parsimony uninformative, and 163 were parsimony informative. The Maximum Likelihood (ML) and Bayesian methods (BM) for phylogenetic analyses produced trees with nearly identical topologies (Bayesian tree not shown). The majority (76 isolates) grouped together in a large clade containing Lasiodiplodia theobromae (CBS 16496). Nine isolates grouped with Lasiodiplodia iraniensis (CBS 124710). Four isolates grouped with Lasiodiplodia brasiliense (CMM 4015) and Lasiodiplodia jatrophicola (CMM 3610). Three isolates grouped with Lasiodiplodia pseudotheobromae (CBS 116459). Two isolates grouped with Lasiodiplodia euphorbicola (CMM
3609) and Lasiodiplodia gonubiensis (CBS 115812), respectively. Ten isolates did not cluster with any known Lasiodiplodia species (Fig 2). The Neofusicoccum combined ITS, EF1- $\alpha$, and TUB dataset (which comprised two isolates from this study and 18 sequences originating from GenBank) comprised 1830 characters, with 1370 constant, 427 variable and parsimony uninformative, and 366 parsimony informative. The two isolates clustered with Neofusicoccum batangarum (CBS 124924). The dataset of combined rDNA ITS and EF1- $\alpha$ sequence data for Pseudofusicoccum species comprised 17 isolates including the outgroup, with comprised total of 1411 characters, of which 


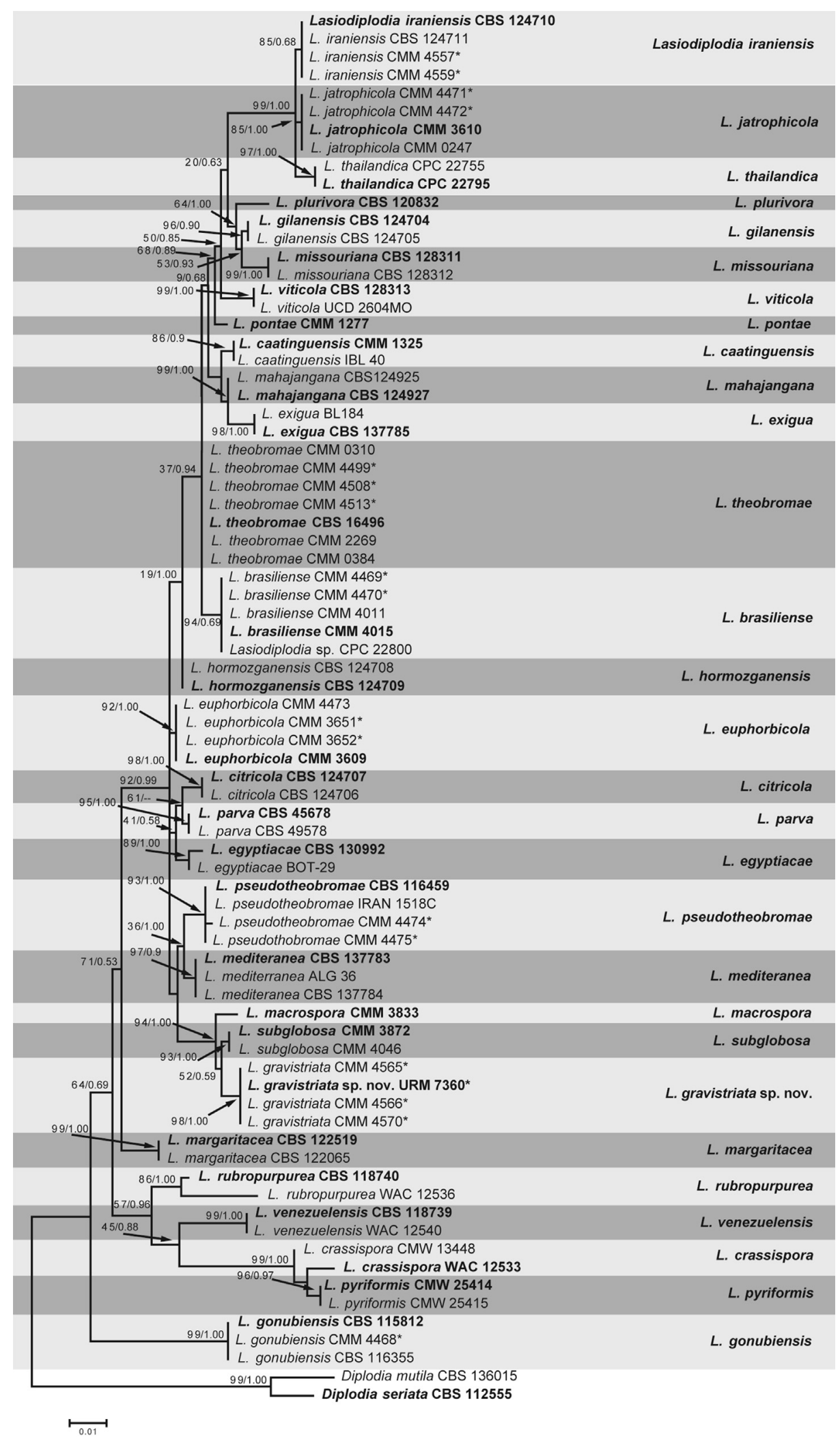

Fig 2 - Maximum likelihood tree resulting from the combined analysis of ITS and EF1- $\alpha$ sequence data. ML Bootstrap support values and Bayesian posterior probability scores are given at the nodes. The tree was rooted to Diplodia mutila and Diplodia seriata. Ex-type isolates are in bold. The scale bar represents the number of substitutions per site. 


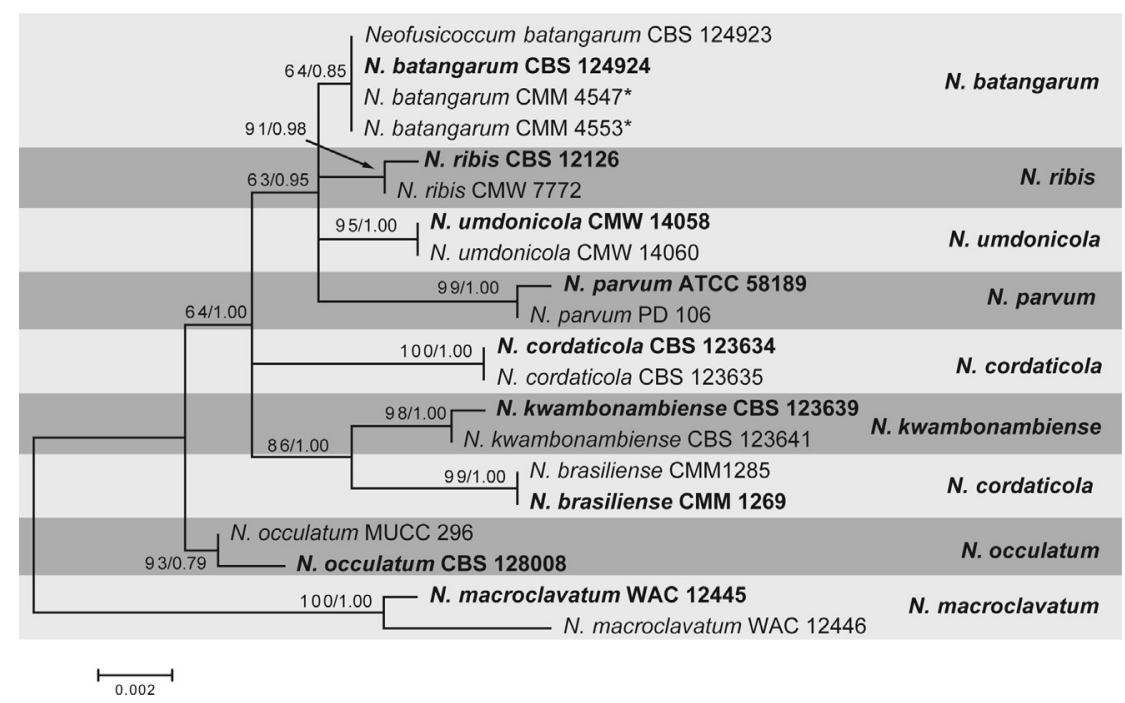

Fig 3 - Maximum likelihood tree resulting from the combined analysis of ITS, EF1- $\alpha$, and $\beta$-tubulin sequence data. ML Bootstrap support values and Bayesian posterior probability scores are given at the nodes. The tree was rooted to Neofusicoccum macroclavatum. Ex-type isolates are in bold. The scale bar represents the number of substitutions per site.

1187 were constant, 162 were variable and parsimony uninformative, and 137 parsimony informative. All 16 isolates clustered with Pseudofusicoccum stromaticum (CMW 13434).

\section{Morphology and cultural characteristics}

All the isolates that were identified based on the phylogenetic analyses using the combined data, comprising 23 Lasiodiplodia isolates [Lasiodiplodia brasiliense (2), L. euphorbicola (1), L. gonubiensis (1), L. iraniensis (5), L. jatrophicola (2), L. gravistriata (5), L. pseudotheobromae (2), and L. theobromae (5)] and the 10 fusicoccum-like isolates [Neofusicoccum batangarum (5) and Pseudofusicoccum stromaticum (5)] were characterized on the basis of colony morphology and conidial characteristics. Growth was rapid for all isolates on PDA, with mycelia covering the entire surface of the Petri dishes. Aerial mycelium was initially white, then turning dark greenish grey or greyish after 4-5 d incubation at $25{ }^{\circ} \mathrm{C}$ in the dark. For all isolates, structures of the asexual morph appeared within 2-4 weeks colonization of PNA. Sexual structures were absent throughout the growth period. All species showed morphological features typical of the genus (Punithalingam 1976, 1980). The new species of Lasiodiplodia described here showed differences in conidial size to previously described species. The conidial dimensions of L. gravistriata were also outside the range previously documented in the literature for this species (Table 2).

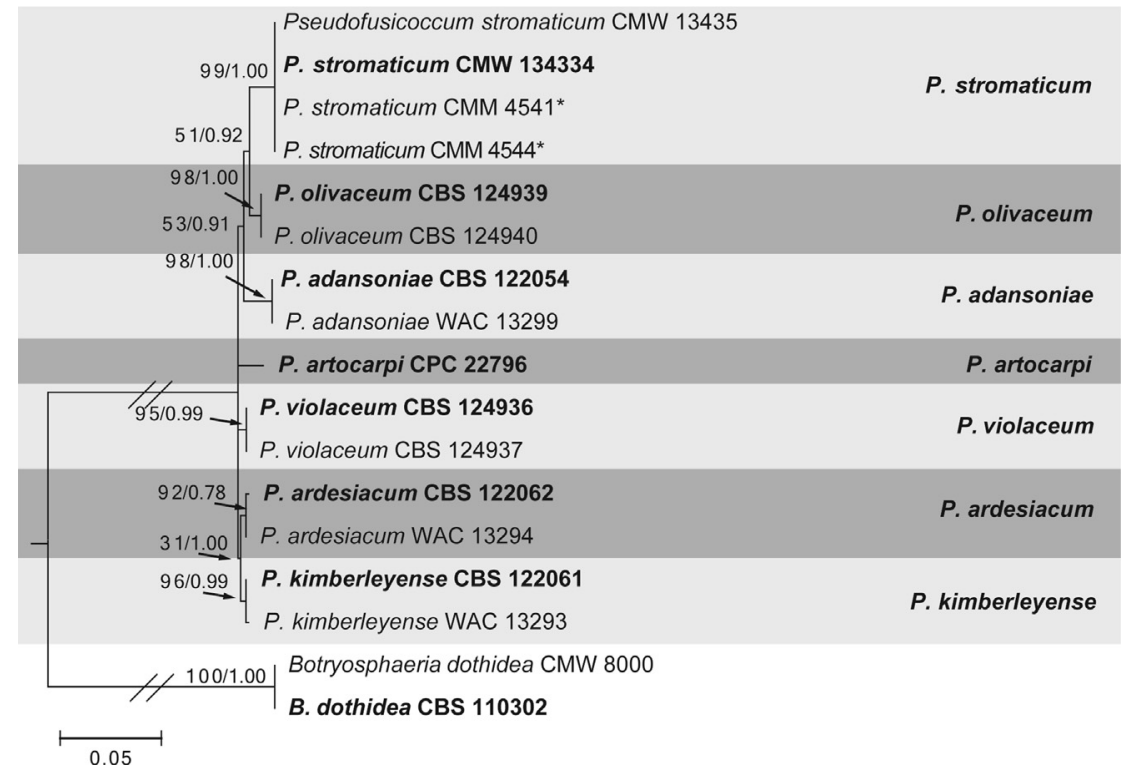

Fig 4 - Maximum likelihood tree resulting from the combined analysis of ITS and EF1- $\alpha$ sequence data. ML Bootstrap support values and Bayesian posterior probability scores are given at the nodes. The tree was rooted to Botryosphaeria dothidea. Extype isolates are in bold. The scale bar represents the number of substitutions per site. 
Only L. gravistriata and L. pseudotheobromae grew at $5{ }^{\circ} \mathrm{C}$ and $10{ }^{\circ} \mathrm{C}$. The optimum temperature for mycelial growth and growth rate differed significantly $(P \leq 0.05)$ among the Botryosphaeriaceae species (Table 3 ). The optimum growth temperature for $\mathrm{N}$. batangarum $\left(27.9^{\circ} \mathrm{C}\right)$ was significantly lower than observed for P. stromaticum $\left(32.3^{\circ} \mathrm{C}\right)$, L. brasiliense $\left(31.2^{\circ} \mathrm{C}\right), \mathrm{L}$. jatrophicola $\left(31.0^{\circ} \mathrm{C}\right)$, and five additional species (L. gravistriata, L. gonubiensis, L. theobromae, L. pseudotheobromae, and L. iraniensis) where temperatures varied from $30.1^{\circ} \mathrm{C}$ to $30.7^{\circ} \mathrm{C}$ (Table 3 ). The mycelial growth rates of L. gravistriata $\left(69.6 \mathrm{~mm} \mathrm{~d}^{-1}\right)$ and L. iraniensis $\left(64.0 \mathrm{~mm} \mathrm{~d}^{-1}\right)$ were significantly higher than those the other seven species, which varied from $24.8 \mathrm{~mm} \mathrm{~d}^{-1}$ ( $\mathrm{L}$. pseudotheobromae) to $53.7 \mathrm{~mm} \mathrm{~d}^{-1}$ (L. theobromae).

\section{Taxonomy}

Lasiodiplodia gravistriata M.S.B. Netto \& M.P.S. Câmara, sp. nov. (Fig 5)

MycoBank No.: MB816925

Etymology: In reference to the pronounced longitudinal striations compared to most species of Lasiodiplodia.

Mycelium immersed or superficial, branched, septate, dark brown. Aerial mycelia becoming olivaceous grey to violaceous black at the surface and dark mouse grey to olivaceous black. Colonies reaching $60 \mathrm{~mm}$ on MEA after $2 \mathrm{~d}$ in the dark at $25^{\circ} \mathrm{C}$. Optimum temperature for mycelia growth at $31.2^{\circ} \mathrm{C}$. Ascomata not seen. Conidiomata stromatic, pycnidial, produced on pine needles on WA within
2-4 weeks, immersed or superficial, dark brown to black, covered with mycelium, mostly uniloculate, solitary, globose, thick-walled, non-papillate with a central ostiole. Paraphyses hyaline, cylindrical, aseptate, rounded at apex. Conidiophores reduced to conidiogenous cells. Conidiogenous cells holoblastic, not proliferating, discrete, hyaline, smooth, thin-walled, cylindrical, 9-14 × 3-5 $\mu \mathrm{m}$. Conidia initially hyaline, aseptate, ellipsoid to ovoid, with granular content, rounded at apex, base mostly truncate, wall $<2 \mu \mathrm{m}$, becoming pigmented, verruculose, ellipsoid to ovoid, 1-septate with longitudinal striations, $24.5-28.5 \times 10.5-16 \mu \mathrm{m}(\mathrm{av} .=26.2 \times 13.8, \mathrm{n}=50)$.

Habitat: On Anacardium humile.

Known distribution: Minas Gerais state, Brazil.

Type: Brazil, Minas Gerais, Coração de Jesus, on Anacardium humile stems, 2013, coll. M. S. B. Netto (holotype URM 89942 dry culture and dry pycnidium produced on pine needles, ex-type culture URM $7360=$ CMM 4564).

Notes: Lasiodiplodia gravistriata is closely related to L. subglobosa, although conidia of L. gravistriata, are longer and narrower than those of L. subglobosa (Table 2). Lasiodiplodia gravistriata differs from its closest phylogenetic neighbour, L. subglobosa, by unique fixed alleles in two genomic DNA loci, based on alignments of the separate loci deposited in TreeBASE as study S19242: rDNA ITS position 23(T); EF$\alpha$ positions 50(T), 56(A), 167(GAP), 187(T), and 227(C). L. gravistriata is also distinguished from $\mathrm{L}$. subglobosa on the basis of conidial size and the prominent longitudinal striations in conidia of L. gravistriata.

Table 2 - Comparison of conidial size of Lasiodiplodia species examined in this study and previous studies.

\begin{tabular}{|c|c|c|c|}
\hline Species & Conidia $(\mu \mathrm{m})$ & L/W ratio & Reference \\
\hline Lasidodiplodia brasiliense & $22.7-29.2 \times 11.7-17.0$ & 1.8 & Netto et al. (2014) \\
\hline L. citricola & $(20-) 24.5(-31) \times(10.9-) 15.4(-19)$ & 1.6 & Abdollahzadeh et al. (2010) \\
\hline L. crassispora & $(27-) 28.8(-33) \times(14-) 16(-17)$ & 1.8 & Burgess et al. (2006) \\
\hline L. egyptiacae & $(17-) 22(-27) \times(11-) 12(-13)$ & 2 & Ismail et al. (2012) \\
\hline L. euphorbicola & $15-23 \times 9-12$ & - & Machado et al. (2014) \\
\hline L. exigua & $(19.6-) 21.8(-24.3) \times(10.8-) 12.3(-13.3)$ & 1.8 & Linaldeddu et al. (2015) \\
\hline L. gilaniensis & $(25.2-) 31(-38.8) \times(14.4-) 16.6(-19)$ & 1.9 & Abdollahzadeh et al. (2010) \\
\hline L. gonubiensis & $(28-) 33.8(-39) \times(14-) 17.3(-21)$ & 1.9 & Pavlic et al. (2004) \\
\hline L. gravistriata & $(24.7-) 26.2(-28.7) \times(10.6-) 13.8(-16.1)$ & 1.9 & Present study \\
\hline L. hormozganensis & $(15.3-) 21.5(-25.2) \times(11-) 12.5(14)$ & 1.7 & Abdollahzadeh et al. (2010) \\
\hline L. iraniensis & $(15.3-) 20.7(-29.7) \times(11-) 13(-14)$ & 1.6 & Abdollahzadeh et al. (2010) \\
\hline L. jatrophicola & $22-26 \times 14-17$ & - & Machado et al. (2014) \\
\hline L. lignicola & $(15-) 16(-17.5) \times(8-) 8.5-10.5(-11)$ & 1.7 & Phillips et al. (2013) \\
\hline L. macrospora & $28-35 \times 15-17$ & - & Machado et al. (2014) \\
\hline L. mahajangana & $(13.5-) 17.5(-21.5) \times(10-) 11.5(-14)$ & 1.4 & Begoude et al. (2010) \\
\hline L. margaritacea & $(12-) 15.3(-19) \times(10-) 11.4(-12.5)$ & 1.3 & Pavlic et al. (2008) \\
\hline L. mediterranea & $(26.3-) 30.6(-37) \times(13.5-) 16.1(-18)$ & 1.9 & Linaldeddu et al. (2015) \\
\hline L. missouriana & $(16.1-) 18.5(-21) \times(8.1-) 9.8(-11.8)$ & 1.9 & Úrbez-Torres et al. (2012) \\
\hline L. parva & $(15.5-) 20.2(-24.5) \times(10-) 11.5(-14.5)$ & 1.8 & Alves et al. (2008) \\
\hline L. plurivora & $(22-) 29.6(-35) \times(13-) 15.6(-18.5)$ & 1.9 & Damm et al. (2007) \\
\hline L. pseudotheobromae & $(22.5-) 28(-33) \times(13.5-) 16(-20)$ & 1.7 & Alves et al. (2008) \\
\hline L. pyriformis & $(19-) 21.5-25(28-) \times(13.5)-15.5-19.5(-21.5)$ & 1.3 & Slippers et al. (2014) \\
\hline L. rubropurpurea & $(24-) 28.2(-33) \times(13-) 14.6(-17)$ & 1.9 & Burgess et al. (2006) \\
\hline L. subglobosa & $16-23 \times 11-17$ & - & Machado et al. (2014) \\
\hline L. thailandica & $(20-) 22-25(-26) \times(12-) 13-15(-16)$ & - & Trakunyingcharoen et al. (2015) \\
\hline L. theobromae & $(19-) 26.2(-32.5) \times(12-) 14.2(-18.5)$ & 1.9 & Phillips et al. (2013) \\
\hline L. venezuelensis & $(26-) 28.4(-33) \times(12-) 13.5(-15)$ & 2.1 & Burgess et al. (2006) \\
\hline L. viticola & $(16.8-) 19.5(-22.9) \times(7.9-) 9.5(-10.7)$ & 2.1 & Úrbez-Torres et al. (2012) \\
\hline
\end{tabular}


Table 3 - Optimum temperature for mycelial growth and mycelial growth rate at $30^{\circ} \mathrm{C}$ of Lasiodiplodia species associated with gummosis of Anacardium in Brazil.

\begin{tabular}{lccc} 
Species & $\mathrm{n}$ & $\begin{array}{c}\text { Optimum } \\
\text { temperature } \\
(\mathrm{C}) \pm \mathrm{SE}\end{array}$ & $\begin{array}{c}\text { Mycelial } \\
\text { growth rate } \\
\left(\mathrm{mm} \mathrm{d}^{-1}\right) \pm \mathrm{SE}\end{array}$ \\
\hline $\begin{array}{l}\text { Lasiodiplodia brasiliense } \\
\text { L. euphorbicola }\end{array}$ & 2 & $31.2 \pm 0.64 \mathrm{ab}$ & $42.0 \pm 3.11 \mathrm{bc}$ \\
L. gonubiensis & 1 & $30.6 \pm 0.42 \mathrm{~b}$ & $56.8 \pm 4.20 \mathrm{ab}$ \\
L. gravistriata & 1 & $28.4 \pm 0.81 \mathrm{~cd}$ & $44.1 \pm 5.18 \mathrm{bc}$ \\
$\begin{array}{l}\text { L. iraniensis } \\
\text { L. jatrophicola }\end{array}$ & 5 & $30.7 \pm 0.40 \mathrm{~b}$ & $69.6 \pm 3.22 \mathrm{a}$ \\
$\begin{array}{l}\text { L. pseudotheobromae } \\
\text { L. theobromae }\end{array}$ & 2 & $30.1 \pm 0.41 \mathrm{bc}$ & $64.0 \pm 3.22 \mathrm{a}$ \\
Neofusicoccum & 2 & $30.1 \pm 0.59 \mathrm{bc}$ & $24.8 \pm 3.15 \mathrm{~d}$ \\
$\quad$ batangarum & 5 & $30.5 \pm 0.36 \mathrm{~b}$ & $53.7 \pm 3.19 \mathrm{~b}$ \\
Pseudofusicoccum & 5 & $27.9 \pm 0.52 \mathrm{~d}$ & $32.0 \pm 3.12 \mathrm{~cd}$ \\
$\quad$ stromaticum & 5 & $32.3 \pm 0.34 \mathrm{a}$ & $33.1 \pm 2.76 \mathrm{~cd}$ \\
\hline
\end{tabular}

Mean \pm standard error. Values within columns followed by the same letter do not differ significantly according to Fisher's LSD test $(P \leq 0.05)$.

\section{Distribution of Botryosphaeriaceae species}

Lasiodiplodia theobromae was the predominant species observed on Anacardium spp. (66.7\%), followed by Lasiodiplodia gravistriata and Neofusicoccum batangarum (7.2\%), Pseudofusicoccum stromaticum and Lasiodiplodia iraniensis (6.5\%), Lasiodiplodia brasiliense, L. jathrophicola and L. pseudotheobromae
(1.4\%), Lasiodiplodia euphorbicola and Lasiodiplodia gonubiensis (0.7\%). The overall distribution of these Botryosphaeria species differed among the Brazilian states sampled. Lasiodiplodia theobromae was found in five Brazilian states (Alagoas, Ceará, Minas Gerais, Pernambuco, and Rio Grande do Norte). Neofusicoccum batangarum was found in four Brazilian states (Alagoas, Ceará, Pernambuco, and Rio Grande do Norte). The new species L. gravistriata, together with L. euphorbicola and L. gonubiensis, were found only in the state of Minas Gerais (Fig 1).

\section{Pathogenicity and virulence on detached green shoots}

All isolates of Botryosphaeriaceae were found to be pathogenic on Anacardium occidentale (cv. BRS 274), with inoculated detached green shoots showing visible lesions $10 \mathrm{~d}$ after inoculation. Dark brown necrotic lesions were observed both on the tissue surface and internally, advancing upwards and downwards from the point of inoculation. Significant differences $(P \leq 0.05)$ in internal lesion lengths were apparent between the examined isolates for the different Botryosphaeriaceae species.

The longest lesions were produced by Neofusicoccum batangarum $(27.0 \mathrm{~mm})$ and Lasiodiplodia iraniensis $(26.2 \mathrm{~mm})$, which were thus considered to be the most aggressive species in this study. By contrast, the shortest lesions were observed for the least aggressive species, Lasiodiplodia euphorbicola and Lasiodiplodia pseudotheobromae ( $<12 \mathrm{~mm}$ ), with lesion size differing significantly from $N$. batangarum and L. iraniensis. The other species (Lasiodiplodia brasiliense, L. gonubiensis, L. jathrophicola, L. gravistriata, L. theobromae, and Pseudofusicoccum
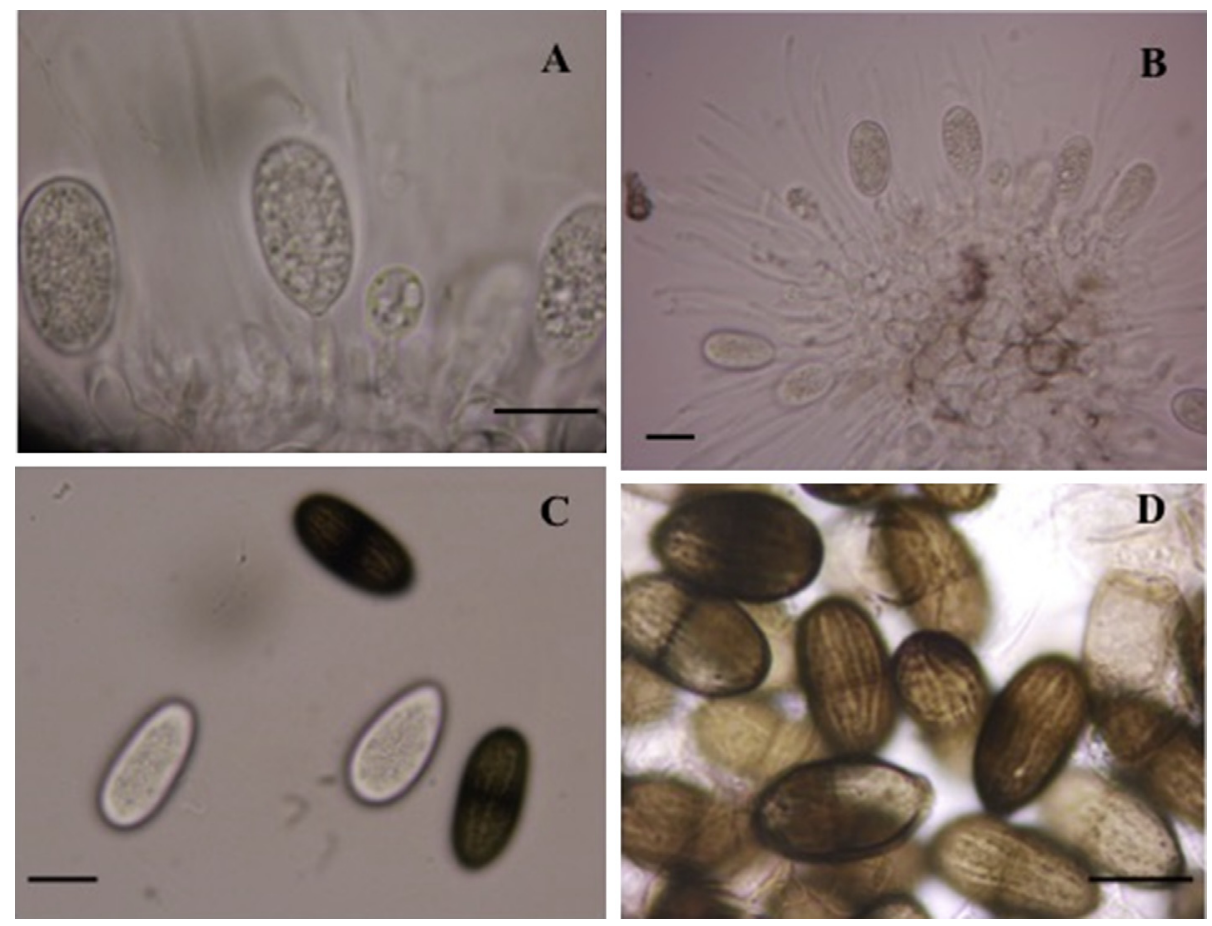

Fig 5 - Lasiodiplodia gravistriata (CMM4564) (A-B). Conidiogenous cells giving rise to conidia; (C). mature conidia in two different focal planes to show the longitudinal striations; (D). brown, 1-septate conidia. Scale bars: (A-D) = $10 \mu \mathrm{m}$. (For interpretation of the references to colour in this figure legend, the reader is referred to the web version of this article.) 
stromaticum) displayed intermediate aggressiveness, with lesions varying in length from $15.5 \mathrm{~mm}$ to $22.2 \mathrm{~mm}$ (Fig 6).

\section{Discussion}

In this study, we describe the species of Botryosphaeriaceae which are associated with gummosis of Anacardium in Brazil. Data were based on morphological, molecular, and pathogenicity testing for a large set of isolates from different growing regions across the country. Ten species of Botryosphaeriaceae were identified associated with gummosis on Anacardium spp.: Lasiodiplodia brasiliense, L. euphorbicola, L. gonubiensis, L. iraniensis, L. jatrophicola, L. gravistriata, L. pseudotheobromae, L. theobromae, Neofusicoccum batangarum, and Pseudofusicoccum stromaticum. With the exception of $L$. theobromae, all the other species described represent first reports on Anacardium.

Following identification, L. theobromae was concluded to be both the most frequent species associated with gummosis of Anacardium, as well as was the most widespread of all the Botryosphaeriaceae species (Fig 1). Similar findings were observed for this species when associated with dieback and stem-end rot of mango (Marques et al. 2013a), stem-end rot of papaya (Netto et al. 2014) and grapevine dieback (Correia et al. 2016) across the semi-arid region of north-eastern Brazil. Such data supports previous descriptions of this species as a pantropical pathogen occurring on a diverse range of hosts plants (Punithalingam 1980; Burgess et al. 2006). In recent years, a number of species have been described in the L. theobromae complex globally, which likely reflects the increased employment of DNA sequence data, as well as sampling of relatively unexplored areas, including Australia (Pavlic et al. 2008), Brazil (Marques et al. 2013a; Machado et al. 2014; Netto et al. 2014; Correia et al. 2016; Coutinho et al. 2016), Egypt

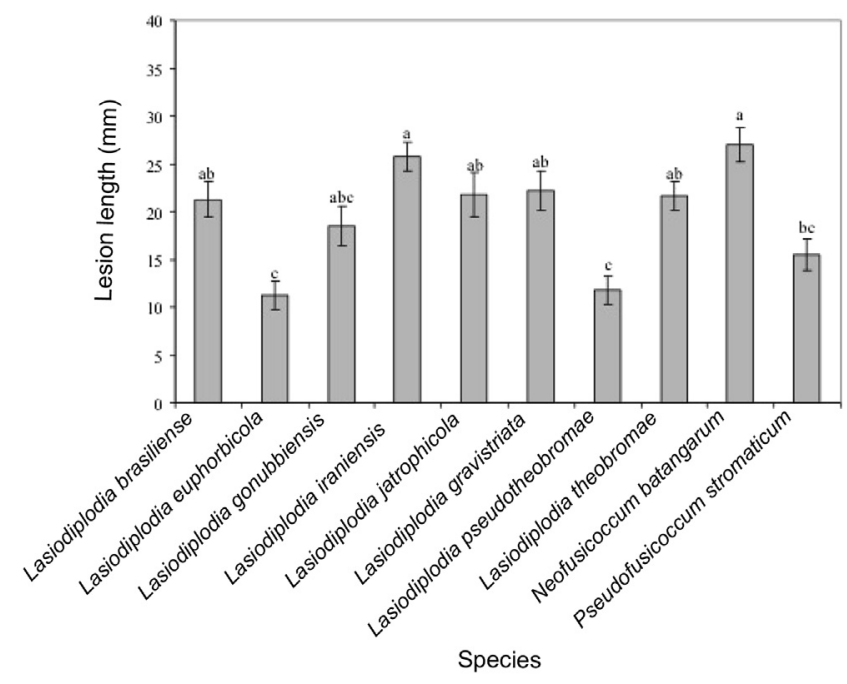

Fig 6 - Mean internal lesion lengths $(\mathrm{mm})$ caused by 10 Botryosphaeriaceae species associated with cashew gummosis in Brazil, $10 \mathrm{~d}$ after inoculation with mycelium colonized agar plugs onto detached green shoots of Anacardium occidentale (cv. BRS 274). Bars above columns are the standard error of the mean. Columns with same letter do not differ significantly according to Fisher's LSD test $(P \leq 0.05)$.
(Ismail et al. 2012), Iran (Abdollahzadeh et al. 2010), Italy, Alergia and Tunisia (Linaldeddu et al. 2015), Oman and The United Arab Emirates (Al-Sadi et al. 2013), Thailand (Trakunyingcharoen et al. 2015), and Venezuela (Burgess et al. 2006).

Lasiodiplodia gravistriata is recognized as a new species in the genus Lasiodiplodia, which is phylogenetically closely related to Lasiodiplodia subglobosa. However, five nucleotides in the EF1- $\alpha$ gene distinguish L. gravistriata from L. subglobosa. The cashew derived isolates of L. gravistriata formed a clade strongly supported in both the Bayesian (1.00) and in the ML (98\%) analyses. Lasiodiplodia gravistriata can also be distinguished from L. subglobosa on the basis of both conidial size, which are longer and narrower than those typical of L. subglobosa (Machado et al. 2014), and the prominent longitudinal striations in which occur in the conidia of this species. This new species was also one of the most frequently occurring as pathogen of Anacardium humile in Brazil (Fig 1), and did not differ in virulence from L. brasiliense, L. iraniensis, L. gonubiensis, L. jatrophicola, L. theobromae, and N. batangarum.

Lasiodiplodia iraniensis was described from Iran on the susceptible hosts Mangifera indica and Juglans sp. (Abdollahzadeh et al. 2010), then subsequently reported in Brazil associated with mango (Marques et al. 2013a). This current work represents the first report of this species as causing gummosis in Anacardium spp. Although L. iraniensis was only moderately prevalent, it was one of the most aggressive species observed following inoculation of detached green cashew shoots, and therefore L. iraniensis should be regarded as a potential threat to this crop. These findings contrast those reported by Marques et al. (2013a), where L. iraniensis isolates produced smaller lesions on mango fruits than other species.

Lasiodiplodia brasiliense was first described in Brazil in 2014 causing stem-end rot of papaya (Netto et al. 2014). Its identification in the present study represents the first report of this species causing gummosis on Anacardium. Although most closely related to Lasiodiplodia viticola based on phylogenetic analyses, conidia in L. brasiliense are longer and wider than those typical of L. viticola. Genomic DNA for this species also differed from $L$. viticola, with specific alleles at ITS nucleotide positions: 2(C), 12(G), 42(T), 46(A), 50(C), 56(GAP), 62(GAP), 75(GAP), 123(T), and 370(A). Lasiodiplodia brasiliense was pathogenic on detached green cashew shoots and one of the least prevalent species associated with Anacardium. This contrasts to reports for this species as being a prevalent species associated with stem-end rot of papaya (Netto et al. 2014) and grapevine dieback (Correia et al. 2016) in the Brazilian São Francisco Valley region.

Prior to this study, L. jatrophicola and L. euphorbicola were described on physic nut in Brazil (Machado et al. 2014). L. jatrophicola is phylogenetically closely related, yet clearly distinct from $L$. iraniensis, with larger conidia and shorter paraphyses typical of this species. Lasiodiplodia euphorbicola is phylogenetically closely related to Lasiodiplodia parva. These two taxa share morphological characteristics, although paraphyses are smaller in L. euphorbicola (Machado et al. 2014). In this study, L. jatrophicola was the one of least prevalent species (0.7\%), and only moderately aggressiveness on Anacardium occidentale. Similarly L. euphorbicola was rarely encountered and showed only low levels of aggressiveness. A similar result 
was found by Correia et al. (2016), where L. jatrophicola and L. euphorbicola isolates displayed moderate and low levels of aggressiveness, respectively, on grapevines. This study report for the first time L. jatrophicola causing gummosis in Anacardium anywhere in the world, and identification of a third host of this species in Brazil.

Lasiodiplodia pseudotheobromae was also identified on A. occidentale in Brazil (Coutinho et al. 2016). Globally, this species, like $L$. theobromae, has a wide distribution and a wide host range, and has been reported on hosts that include Acacia, Citrus, Coffea, Gmelina, and Rosa species (Alves et al. 2008; Phillips et al. 2008; Abdollahzadeh et al. 2010; Perez et al. 2010; Sakalidis et al. 2011; Ismail et al. 2012; Slippers et al. 2014; Trakunyingcharoen et al. 2015). In Brazil, L. pseudotheobromae has so far been reported on mango (Marques et al. 2013a), physic nut (Machado et al. 2014), papaya (Netto et al. 2014), and grapevine (Correia et al. 2016). Morphologically, this species differs from $\mathrm{L}$. theobromae in terms of conidial dimension and form, with conidia generally being larger, more ellipsoid and with less pronounced tapering towards the base (Alves et al. 2008). In terms of pathogenicity, L. pseudotheobromae was the most aggressive species on mango in Australia (Sakalidis et al. 2011), and Egypt (Ismail et al. 2012) as well as on Terminalia catappa (Combretaceae) in Cameroon (Begoude et al. 2010). Here, by contrast, L. pseudotheobromae was only moderately aggressiveness on cashew shoots, and was reported on mango (Marques et al. 2013a), papaya (Netto et al. 2014), grape (Correia et al. 2016), and cashew (Coutinho et al. 2016) in Brazil.

Lasiodiplodia gonubiensis was the first species for the genus to be reported on native trees in South Africa, where it was encountered as an endophytic fungus of Syzygium cordatum (Pavlic et al. 2004). The present study represents the first report of L. gonubiensis in Brazil and causing gummosis on Anacardium. Here, this species was isolated infrequently on A. occidentale, with aggressiveness on this host similar to levels observed for L. brasiliense, L. jatrophicola, L. theobromae, and P. stromaticum.

The application of molecular tools has facilitated the recognition of species in the Botryosphaeriaceae, with numerous species recently described on native vegetation, and economically important crops (Liu et al. 2012; Phillips et al. 2013). In this work, two additional genera were identified as associated with gummosis on Anacardium: N. batangarum and P. stromaticum. Information on $\mathrm{N}$. batangarum is scarce given it was only recently described (Begoude et al. 2010). This fungus was reported as an endophytic fungus on T. catappa in Cameroon (Shetty et al. 2011). As this fungus can cause pathogenic reactions on T. catappa under greenhouse conditions (Begoude et al. 2010), however, the fungus may therefore switch from an endophytic life style in plant organs to aggressive pathogen, when environmental conditions become unfavourable for the tree host. In this study, this species was frequently isolated from A. occidentale and produced the largest lesions on detached cashew green shoots.

Pseudofusicoccum stromaticum was also an abundant species, indicating this genus to be more widely distributed than earlier considered. Previously, this species has been found on Eucalyptus and Acacia spp. in Venezuela (Mohali et al. 2006; 2007) and on mango in Brazil (Marques et al. 2012). Pavlic et al. (2008) also reported Pseudofusicoccum spp. on native hosts plants in undisturbed areas in Australia, providing evidence for these species to be native to the country. Our study contradicts this suggestion, with P. stromaticum found in Brazil on native cashew (Anacardium othonianum).

Optimum growth temperatures of Botryosphaeriaceae species varied from $27.9^{\circ} \mathrm{C}$ to $32.3^{\circ} \mathrm{C}$. Lasiodiplodia gravistriata and L. pseudotheobromae also grew at as low as $5^{\circ} \mathrm{C}$ and $10^{\circ} \mathrm{C}$. Such growth of L. pseudotheobromae at low temperatures contradicts a number of previous studies (Abdollahzadeh et al. 2010; Marques et al. 2013a; Netto et al. 2014), although other studies (Alves et al. 2008; Ismail et al. 2012) clearly provide data showing that these Lasiodiplodia species have a much wider temperature range than was previously assumed.

In summary, this paper reports 10 species of Botryosphaeriaceae associated with Anacardium in Brazil. L. theobromae, although the species most frequently observed on this host, is neither the exclusive etiologic agent nor the most aggressive species. All species showed potential to cause cashew gummosis, with the species $N$. batangarum and L. iraniensis identified as the most aggressive species. Continued investigation of the epidemiology and impact of gummosis on cashew production is necessary, together with improved understanding of the ecology, distribution, host range, and fungicide sensitivity of all Botryosphaeriaceae species reported on Anacardium. Such information will be crucial for the development of novel gummosis control strategies and genetic improvement of cashew for resistance to biotic stress.

\section{Acknowledgements}

This work was financed by Conselho Nacional de Desenvolvimento Científico e Tecnológico (CNPq-Brazil). M. P. S. Câmara, S. J. Michereff and R. N. G. Miller acknowledge support from the CNPq as research fellow. Mariote S. B. Netto acknowledges support from the CNPq program 'Ciência sem Fronteiras'. The authors also thank Dr Vinson P. Doyle for revising the English text.

\section{R E F E R E N C E S}

Abdollahzadeh J, Javadi A, Mohammadi EG, Zare R, Phillips AJL, 2010. Phylogeny and morphology of four new species of Lasiodiplodia from Iran. Persoonia 25: 1-10.

Agrianual, 2015. Anuário da agricultura brasileira. Informa Economics/FNP, South America, São Paulo.

Aliyu OM, 2012. Genetic diversity of Nigerian cashew germplasm. In: Caliskan M (ed.), Genetic Diversity in Plants. InTech, Rijeka, pp. 163-184.

Al-Sadi AM, Al-Wehaibi AN, Al-Shariqi RM, Al-Hammadi MS, AlHosni IA, Al-Mahmooli IH, Al-Ghaithi AG, 2013. Population genetic analysis reveals diversity in Lasiodiplodia species infecting date palm, Citrus, and mango in Oman and the UAE. Plant Disease 97: 1363-1369.

Alves A, Crous PW, Correia A, Phillips AJL, 2008. Morphological and molecular data reveal cryptic speciation in Lasiodiplodia theobromae. Fungal Diversity 28: 1-13.

Amponsah NT, Jones EE, Ridgway HJ, Jaspers MV, 2011. Identification, potential inoculum sources and pathogenicity of botryosphaeriaceous species associated with grapevine dieback 
disease in New Zealand. European Journal of Plant Pathology 131: 467-482.

Begoude BAD, Slippers B, Wingfield MJ, Roux J, 2010. Botryosphaeriaceae associated with Terminalia catappa in Cameroon, South Africa and Madagascar. Mycological Progress 9: 101-123.

Burgess TI, Barber PA, Mohali S, Pegg G, de Beer W, Wingfield MJ, 2006. Three new Lasiodiplodia spp. from the tropics, recognized based on DNA sequence comparisons and morphology. Mycologia 98: 423-435.

Cardoso JE, Santos AA, Rossetti AG, Vidal JC, 2004. Relationship between incidence and severity of cashew gummosis in the semi-arid Brazilian. Plant Pathology 53: 363-367.

Correia KC, Silva MA, Morais Júnior MA, Armengol J, Phillips AJL, Câmara MPS, Michereff SJ, 2016. Phylogeny, distribution and pathogenicity of Lasiodiplodia species associated with dieback of table grape in the main Brazilian exporting region. Plant Pathology 65: 92-103.

Coutinho IBL, Freire FCO, Lima CS, Lima JS, Gonçalves FJT, Machado AR, Silva AMS, Cardoso JE, 2016. Diversity of genus Lasiodiplodia associated with perennial tropical fruit plants in northeastern Brazil. Plant Pathology. http://dx.doi.org/10.1111/ppa12565.

Costa VSO, Michereff SJ, Martins RB, Gava CAT, Mizubuti ESG, Câmara MPS, 2010. Species of Botryosphaeriaceae associated on mango in Brazil. European Journal of Plant Pathology 127: 509-519.

Cysne AQ Cardoso JE, Maia AHN, Farias FC, 2010. Spatial-temporal analysis of gummosis in three cashew clones at northeastern. Brazilian Journal of Phytopathology 158: 676-682.

Damm U, Crous PW, Fourie PH, 2007. Botryosphaeriaceae as potential pathogens of Prunus species in South Africa, with descriptions of Diplodia africana and Lasiodiplodia plurivora sp. nov. Mycologia 99: 664-680.

De Wet J, Slippers B, Preisig O, Wingfield DB, Wingfield MJ, 2008. Phylogeny of the Botryosphaeriaceae reveals patterns of host association. Molecular Phylogenetics and Evolution 46: 116-126.

Freire FCO, 1991. A resinose do cajueiro (The Cashew Gummosis). Embrapa Centro Nacional de Pesquisa do Caju, Fortaleza.

Freire FCO, Cardoso JE, Santos AA, Viana FMP, 2002. Diseases of cashew (Anacardium occidentale L.) in Brazil. Crop Protection 21: 489-494.

Glass NL, Donaldson GC, 1995. Development of primer sets designed for use with the PCR to amplify conserved genes from filamentous ascomycetes. Applied Environmental Microbiology 61: 1323-1330.

Guindon S, Dufayard JF, Lefort V, Anisimova M, Hordijk W, Gascuel O, 2010. New algorithms and methods to estimate maximum-likelihood phylogenies: assessing the performance of PhyML 3.0. Systematic Biology 59: 307-321.

Hillis DM, Bull JJ, 1993. An empirical test of bootstrapping as a method for assessing confidence in phylogenetic analysis. Systematic Biology 42: 182-192.

Ismail AM, Cirvilleri G, Polizzi G, Crous PW, Groenewald JZ, Lombard L, 2012. Lasiodiplodia species associated with dieback disease of mango (Mangifera indica) in Egypt. Australasian Plant Pathology 41: 649-660.

Kearse M, Moir R, Wilson A, Stones-Havas S, Cheung M, Sturrock S, Buxton S, Cooper A, Markowitz S, Duran C, Thierer T, Ashton B, Mentjies P, Drummond A, 2012. Geneious Basic: an integrated and extendable desktop software platform for the organization and analysis of sequence data. Bioinformatics 28: 1647-1649.

Larget B, Simon D, 1999. Markov chain Monte Carlo algorithms for the Bayesian analysis of phylogenetic trees. Molecular Biology and Evolution 16: 750-759.

Linaldeddu BT, Deidda A, Scanu B, Franceschini A, Serra S, BerrafTebbal A, ZouaouiBoutiti M, Ben Jamaa ML, Phillips AJL, 2015. Diversity of Botryosphaeriaceae species associated with grapevine and other woody hosts in Italy, Algeria and Tunisia, with descriptions of Lasiodiplodia exigua and Lasiodiplodia mediterranea sp. nov. Fungal Diversity 71: 201-214.

Liu JK, Phookamsak R, Doilom M, Wikee S, Li YM, Ariyawansha H, Boonmee S, Chomnunti P, Dai DQ, Bhat JD, Romero AI, Zhuang WY, Monkai J, Jones EBG, Chukeatirote E, KoKo TW, Zhao YC, Wang Y, Hyde KD, 2012. Towards a natural classification of Botryosphaeriales. Fungal Diversity 57: 149-210.

Machado AR, Pinho DB, Pereira OL, 2014. Phylogeny, identification and pathogenicity of the Botryosphaeriaceae associated with collar and root rot of the biofuel plant Jatropha curcas in Brazil, with a description of new species of Lasiodiplodia. Fungal Diversity 67: 231-247.

Marques MW, Lima NB, Michereff SJ, Câmara MPS, Souza CRB, 2012. First report of mango dieback caused by Pseudofusicoccum stromaticum in Brazil. Plant Disease 96: 144-145.

Marques WM, Lima NB, Morais Júnior MA, Barbosa MAG, Souza BO, Michereff SJ, Phillips AJL, Câmara MPS, 2013a. Species of Lasiodiplodia associated with mango in Brazil. Fungal Diversity 61: 181-193.

Marques MW, Lima NB, Morais Júnior MA, Michereff SJ, Phillips AJL, Câmara MPS, 2013b. Botryosphaeria, Neofusicoccum, Neoscytalidium and Pseudofusicoccum species associated with mango in Brazil. Fungal Diversity 61: 195-208.

Mohali S, Slippers B, Wingfield MJ, 2006. Two new Fusicoccum species from Acacia and Eucalyptus in Venezuela, based on morphology and DNA sequence data. Mycological Research 110: 405-413.

Mohali S, Slippers B, Wingfield MJ, 2007. Identification of Botryosphaeriaceae from Eucalyptus, Acacia and Pinus in Venezuela. Fungal Diversity 25: 103-125.

Moreira RC, Lima JS, Silva LGC, Cardoso JE, 2013. Resistance to gummosis in wild cashew genotypes in northern Brazil. Crop Protection 52: 10-13.

Muniz CR, Freire FCO, Viana FMP, Cardoso JE, Correia D, Jalink H, Kema GHJ, Silva GF, Guedes MIF, 2012. Polyclonal antibodybased ELISA in combination with specific PCR amplification of internal transcribed spacer regions for the detection and quantitation of Lasiodiplodia theobromae, causal agent of gummosis in cashew nut plants. Annals of Applied Biology 160: 217-224.

Netto MSB, Assunçao IP, Lima GSA, Marques MW, Lima WG, Monteiro JHA, Balbino VQ, Michereff SJ, Phillips AJL, Câmara MPS, 2014. Species of Lasiodiplodia associated with papaya stem-end rot in Brazil. Fungal Diversity 67: 127-141.

Pavlic D, Slippers B, Coutinho TA, Gryzenhout M, Wingfield MJ, 2004. Lasiodiplodia gonubiensis sp. nov., a new Botryosphaeria anamorph from native Syzygium cordatum in South Africa. Studies in Mycology 50: 313-322.

Pavlic D, Wingfield MJ, Barber P, Slippers B, Hardy GESJ, Burgess TI, 2008. Seven new species of the Botryosphaeriaceae from baobab and other native trees in Western Australia. Mycologia 100: 851-866.

Pérez CA, Wingfield MJ, Slippers B, Altier NA, Blanchette RA, 2010. Endophytic and canker-associated Botryosphaeriaceae occurring on non-native Eucalyptus and native Myrtaceae trees in Uruguay. Fungal Diversity 41: 53-69.

Phillips AJL, 2006. The Botryosphaeria Site. http://www.crem.fct.unl. pt/botryosphaeria_site/.

Phillips AJL, Alves A, Correia A, Luque J, 2005. Two new species of Botryosphaeria with brown, 1-septate ascospores and Dothiorella anamorphs. Mycologia 97: 513-529.

Phillips AJL, Alves A, Pennycook SR, Johnston PR, Ramaley A, Akulov A, Crous PW, 2008. Resolving the phylogenetic and taxonomic status of dark-spored teleomorph genera in the Botryosphaeriaceae. Persoonia 21: 29-55.

Phillips AJL, Alves A, Abdollahzadeh J, Slippers B, Wingfield MJ, Groenewald JZ, Crous PW, 2013. The Botryosphaeriaceae: genera and species known from culture. Studies in Mycology 76: 51-167. 
Punithalingam E, 1976. Botryodiplodia theobromae. CMI Descriptions of Pathogenic Fungi and Bacteria, No. 519. Common wealth Mycological Institute, Kew.

Punithalingam E, 1980. Plant Diseases Attributed to Botryodiplodia theobromae Pat. Cramer, Vaduz.

Rambaut A, 2009. FigTree, v.1.4.1. http://tree.bio.ed.ac.uk/software/ figtree/.

Rannala B, Yang Z, 1996. Probability distribution of molecular evolutionary trees: a new method of phylogenetic inference. Journal of Molecular Evolution 43: 304-311.

Rayner RW, 1970. A Mycological Colour Chart. Common wealth Mycological Institute and British Mycological Society, Kew.

Rodríguez F, Oliver JL, Marin A, Medina JR, 1990. The general stochastic model of nucleotide substitution. Journal of Theoretical Biology 142: 485-501.

Ronquist F, Huelsenbeck JP, 2003. MrBayes3: Bayesian phylogenetic inference under mixed models. Bioinformatics 19: 1572-1574.

Sakalidis ML, Hardy GESJ, Burgess TI, 2011. Endophytes as potential pathogens of the baobab species Adansonia gregorii: a focus on the Botryosphaeriaceae. Fungal Ecology 4: 1-14.

Shetty KG, Minnis AM, Rossman AY, Jayachandran K, 2011. The Brazilian peppertree seed-borne pathogen, Neofusicoccum batangarum, a potential biocontrol agent. Biological Control 56: 91-97.

Slippers B, Crous PW, Denman S, Coutinho TA, Wingfield BD, Wingfield MJ, 2004a. Combined multiple gene genealogies and phenotypic characters differentiate several species previously identified as Botryosphaeria dothidea. Mycologia 96: 83-101.
Slippers B, Fourie G, Crous PW, Coutinho TA, Wingfield BD, Wingfield MJ, 2004b. Multiple gene sequences delimit Botryosphaeria australis sp. nov. from B. lutea. Mycologia 96: 1028-1039.

Slippers B, Roux J, Wingfield MJ, van der Walt FJJ, Jami F, Mehl JWM, Marais GJ, 2014. Confronting the constraints of morphological taxonomy in the Botryosphaeriales. Persoonia 33: 155-168.

Slippers B, Wingfield MJ, 2007. Botryosphaeriaceae as endophytes and latent pathogens of woody plants: diversity, ecology and impact. Fungal Biology Reviews 21: 75-89.

Sutton BC, 1980. The Coelomycetes: fungi imperfecti with pycnidia, acervuli and stromata. Commonwealth Mycological Institute, Kew.

Thompson JD, Gibson TJ, Plewniak F, Jeanmougin F, Higgins DG, 1997. The ClustalX windows interface: flexible strategies for multiple sequence alignment aided by quality analysis tools. Nucleic Acids Research 25: 4876-4882.

Trakunyingcharoen T, Lombard L, Groenewald JZ, Cheewangkoon R, To-anun C, Crous PW, 2015. Caulicolous Botryosphaeriales from Thailand. Persoonia 34: 87-99.

Úrbez-Torres JR, Peduto F, Striegle RK, Urrea-Romero KE, Rupe JC, Cartwright RD, Gubler WD, 2012. Characterization of fungal pathogens associated with grapevine trunk diseases in Arkansas and Missouri. Fungal Diversity 52: 169-189.

White TJ, Bruns T, Lee S, Taylor J, 1990. Amplification and direct sequencing of fungal ribosomal RNA genes for phylogenetics. In: Innis MA, Gelfand DH, Sninsky JJ, White TJ (eds), PCR Protocols, a Guide to Methods and Applications. Academic, San Diego, pp. 315-322.

Young ND, Healey J, 2003. GapCoder automates the use of indel characters in phylogenetic analysis. BMC Bioinformatics 4: 6. http: //www.biomedcentral.com/content/pdf/1471-2105-4-6.pdf. 